\title{
- Development of Irinotecan Dissolution Rate by Snedds
}

IJCRR
Section: Healthcare
ISI Impact Factor
$(2020-21): 1.899$
IC Value (2020): 91.47
SJIF (2020) = 7.893
Co) ()

\author{
Maddela Chandra Shekhar ${ }^{1 *}$, Pamu Sandhya² \\ 'Research Scholar, Career Point University, Kota, Rajasthan-325003, India; ${ }^{2}$ Research Supervisor, Career Point University, Kota, Rajasthan-325003, \\ India.
}

\section{ABSTRACT}

Introduction: Irinotecan being anti-neoplastic agent belongs to BCS class II drug with low solubility and permeability that undergoes first-pass metabolism, leading to reduced bioavailability of $9 \%$.

Aim: The main objective of this study is to develop irinotecan supersaturble-self nano emulsifying drug delivery system (SSNEDDS) for enhancing solubility and oral bioavailability.

Methodology: An oil, surfactant and co-surfactant (canola oil - caproic acid - propylene glycol) are chosen based on the maximum solubility of irinotecan and ratios optimised by constructing pseudo ternary phase diagram and evaluated. The best formulation was chosen for screening of precipitation inhibitor (PI), and based on in-vitro release studies best S-SNEDDS is finalised. Final optimised formulation was characterised for FTIR, particle size, zeta potential, SEM and stability studies.

Results: From evaluation studies of irinotecan, formulation F12 displayed maximum drug content(99\%), maximum entrapment efficiency(99\%) and maximum drug release of $99.96 \%$ in $60 \mathrm{~min}$, hence chosen for screening precipitation inhibitor(PI).The F12 containing 2\% HPMC AS as PI was found to show high release profile. The particle size for the optimized formulation of SSNEDDS (F12) was found to be 128.23nm with PDI 0.137 and the zeta potential value of

$-23.45 \mathrm{mV}$. The FTIR and SEM studies did not indicate any drug excipient interaction and confirm nanosized particles that are stable.

Conclusion: Hence the results reveal that, application of S-SNEDDS formulation technique for irinotecan increased solubility and oral bioavailability.

Key Words: Irinotecan, S-SNEDDS, precipitation inhibitor, Solubility, Particle size, Zeta potential

\section{INTRODUCTION}

Nanotechnology is a rapidly emerging scientific field that is defined as the production of devices with atomic or molecular scale precision, but it also includes all devices with size less than $100 \mathrm{~nm}$. Since their introduction, nanoparticles (NPs) have been proposed as drug carriers, most notably due to their stability-related aspects, their ability to load drugs efficiently, and their control over physicochemical properties. Furthermore, localized drug delivery may be achieved by using macroscopic drug depots close to the target site in addition to systemic administration. ${ }^{1}$

The chemical structure of irinotecan is equivalent to the natural alkaloid camptothecin. Irinotecan is a chemotherapy agent that is a topoisomerase inhibitor. Patients with metastatic carcinomas of the colon or rectum who have failed to respond to initial fluorouracil-based antineoplastic therapy can receive this drug as a single agent.

It has poor aqueous solubility $(0.107 \mathrm{mg} / \mathrm{ml})$ in water at $25^{\circ} \mathrm{C}$ and it is classified under to BCS class II. To overcome these inherent drawbacks an attempt will be made to formulate self nano-emulsifying drug delivery system (SNEDDS). ${ }^{2,3,4,5}$

The present study is pointed to develop canola oil-based irinotecan S-SNEDDS for increasing solubility and thereby release characteristics.

Corresponding Author:

M. Chandra Shekhar, Research Scholar, Career Point University, Kota, Rajasthan-325003, India.

E-mail:srishekharm@gmail.com

ISSN: 2231-2196 (Print) ISSN: 0975-5241 (Online)

Received: $10.04 .2021 \quad$ Revised: 02.08 .2021

Accepted: 12.11 .2021

Published: 01.03 .2022 


\section{MATERIALS AND METHODS}

\section{Materials}

Irinotecan is a gift sample from Hetero Labs Limited, Hyderabad, India. The oils used were purchased from local market. Surfactants and cosurfactants purchased from Gattefosse, Mumbai.

\section{Methods}

\section{Solubility of irinotecan in vehicles}

An excess amount of irinotecan mixed with $1 \mathrm{~g}$ of vehicle in glass vials and vortexed for 10 min followed by shaking reciprocally for $48 \mathrm{~h}$ at $25^{\circ} \mathrm{C}$. The contents and allowed to stand undisturbed for $24 \mathrm{~h}$ at $25^{\circ} \mathrm{C}$. The contents centrifuged at $3000 \mathrm{rpm}$ for $10 \mathrm{~min}$, supernatant filtered, diluted with methanol and analysed for irinotecan spectrophotometrically at $365 \mathrm{~nm}^{6,7}$

\section{Construction of pseudo-ternary phase diagrams}

The chosen vehicles were mixed in various ratios ranging from 1:9 to 9:1 (oil: $\mathrm{S}_{\text {mix }}$ ). $\mathrm{S}_{\text {mix }}$ is the mixture of surfactant and co-surfactant prepared in defined ratios of 1:1,2:1, and $3: 1$. Phase diagrams of surfactant, co-surfactant, and oil were plotted, with each representing an apex of the triangle. Varying ratios of oil: $\mathrm{S}_{\text {mix }}$ were mixed with $100 \mathrm{ml}$ of water and ratios with no phase separation and turbidity were checked for the transmittance (The samples with transmittance $>90$ were used for plotting pseudo-ternary phase diagram using CHEMIX software. ${ }^{8}$

\section{Effect of irinotecan loading}

Twenty compositions of varying ratios of canola oil - caproic acid - propylene glycol were taken and in $1 \mathrm{ml}$ composition of each ratio were incorporated with $25 \mathrm{mg}$ and $50 \mathrm{mg}$ of irinotecan. Contents vortexed at $40^{\circ} \mathrm{C}$ and transmission determined at $365 \mathrm{~nm}$. The area of nano emulsification region was identified as described above by constructing ternary phase diagrams. ${ }^{9}$

\section{Preparation and evaluation of irinotecan SNEDDS}

A series of SNEDDS (F1- F16) were selected from $25 \mathrm{mg}$ loaded irinotecan system and prepared as described above. ${ }^{8}$ About $1 \mathrm{ml}$ of the formulation (equivalent to $25 \mathrm{mg}$ of the irinotecan) was filled in size ' 00 ' hard gelatin capsules, sealed and stored at ambient temperature $\left(25^{\circ} \mathrm{C}\right)$ and evaluated. ${ }^{10}$ (table 1)

\section{EVALUATIONS OF SNEDDS}

\section{Visual observations}

To assess the self-emulsification properties, irinotecan
SNEDDS $(25 \mathrm{mg})$ was introduced into $50 \mathrm{~mL}$ of distilled water in a glass Erlenmeyer flask at $37^{\circ} \mathrm{C}$ and the contents were gently stirred manually. ${ }^{11}$ After equilibrium, time of self-emulsification, dispersibility and appearance were observed and rated according to grading system. ${ }^{12}$

\section{Turbidity measurement}

Turbidity of the prepared dispersions was measured using Nephelo Turbidity Meter using $30 \mathrm{~mL}$ of the dispersion. ${ }^{13}$

\section{Robustness to dilution}

Robustness of irinotecan SNEDDS to dilution was studied by diluting $25 \mathrm{mg}$ of SNEDDS with 50, 100 and $1000 \mathrm{~mL}$ of distilled water, $0.1 \mathrm{~N} \mathrm{HCl}, \mathrm{pH} 4.5$ acetate buffer and $\mathrm{pH} 6.8$ phosphate buffer. The diluted nanoemulsions were stored for $24 \mathrm{~h}$ and observed for any signs of phase separation or drug precipitation. ${ }^{14}$

\section{Percentage drug content}

Individually weighed samples were dissolved in $10 \mathrm{~mL}$ of methanol using a vortex mixer and agitated for 10 minutes. Each of the solutions was filtered, and the drug content of each filtrate was estimated UV spectrophotometrically against blank at $365 \mathrm{~nm} .{ }^{15}$

\section{Entrapment efficiency}

A known quantity of SNEDDS mixed with $100 \mathrm{~mL}$ phosphate buffer ( $\mathrm{pH}$ 7.4) and kept in dark for $24 \mathrm{~h}$. The contents filtered, filtrate diluted and analysed for drug content by UV for the drug content at entrapment efficiency was calculated by formula

Experimental drug content x 100
Drug entrapment efficiency $=$ -
Theoretical drug content

\section{In vitro dissolution study}

In vitro dissolution studies performed using USP dissolution Apparatus II (Lab india DS 8000, Mumbai, India). Hard gelatin capsules, size "1" filled with SNEDDS formulation were mixed with $900 \mathrm{~mL}$ of freshly prepared $\mathrm{pH} 7.4$ phosphate buffer maintained at $37 \pm 0.5^{\circ} \mathrm{C}$ and centrifuged at 100 rpm. ${ }^{16}$ At pre-determined time intervals, $5 \mathrm{~mL}$ of samples were withdrawn and contents replaced with $5 \mathrm{~mL}$ of fresh medium. The samples evaluated spectrophotometrically at $365 \mathrm{~nm}^{17}$

\section{Screening for a precipitation inhibitor (PI)}

In vitro precipitation experiments were used to estimate the apparent drug concentration-time profile and the duration of the super- saturated state. Polymers such as microcrystalline cellulose, HPMC E50LV, HPMC AS and Poloxamer 407 were employed to stabilize the supersaturated irinotecan solution. 
$1 \mathrm{~g}$ of SNEDDS mixed with $100 \mathrm{~mL}$ of simulated gastric fluid (SGF) at $37^{\circ} \mathrm{C}$ and centrifuged. $1 \mathrm{ml}$ sample withdrawn at regular time intervals and centrifuged at $3000 \mathrm{rpm}$ for $3 \mathrm{~min}$ followed evaluation of drug content at $365 \mathrm{~nm} .{ }^{18}$

\section{CHARACTERIZATION OF OPTIMISED IRINOTECAN SNEDDS}

The samples were analyzed by FT-IR spectrophotometer with data acquisition system OPUS. ${ }^{19}$

The globule size and zeta potential determined by a Zetasizer Nano ZS90 dynamic light scattering particle size analyzer (Malvern Instruments, Malvern, Worcestershire, UK). The Scanning electron microscopy (SEM) studies carried out using JEOL JEM $2100 \mathrm{~F}$, USA equipment. ${ }^{20}$

\section{Forced degradation and accelerated stability studies}

All solutions for use in forced degradation studies were prepared by dissolving samples methanol and diluted with the respective forced degradation medium (table 3 ). The samples analysed at various time intervals spectrophotometrically. ${ }^{21,22}$

\section{Accelerated stability studies}

All formulations filled in hard gelatin capsules were packed in HDPE screw capped bottles and kept in humidity chambers maintained at $40 \pm 2^{\circ} \mathrm{C} / 75 \pm 5 \% \mathrm{RH}$ as per ICH guidelines for Zone III and stored for 6 months.

\section{RESULTS AND DISCUSSION}

\section{Determination of irinotecan solubility in vari- ous excipients}

Canola oil was selected as oil phase due to its higher solubilization $(19.54 \pm 0.26 \mathrm{mg} / \mathrm{ml})$ of irinotecan compared to other oils (figure 1). Surfactant (caproic acid) and co-surfactant (propylene glycol) was selected for further studies due to their higher solubilizing capacity towards irinotecan (figure 2,3).

\section{Construction of ternary phase diagrams}

The region of nano emulsification was indicated as shadow area encircled by a solid line and the points indicate the compositions of the system explored. Canola oil - caproic acid - propylene glycol system with $\mathrm{S}_{\text {mix }}$ ratio in 3:1 exhibited larger nanoemulsification region as compared to 1:1 and 2:1 $\mathrm{S}_{\text {mix }}$ ratio (figure 4).

\section{Effect of irinotecan loading}

The area of nano emulsification was considerably reduced with increase in irinotecan loading in to the canola oil - caproic acid
- propylene glycol system with $3: 1 \mathrm{~S}_{\text {mix }}$ ratio hence for the stability reasons of the SNEDDS, system containing $25 \mathrm{mg}$ of irinotecan was chosen for formulation of irinotecan SNEDDS and further studies.(Figure 5)

From the results it was found that canola oil concentration in the range of $22-75 \% \mathrm{w} / \mathrm{w}$, caproic acid in the range of 18 $59 \% \mathrm{w} / \mathrm{w}$ and propylene glycol in the range of $6-19 \% \mathrm{w} / \mathrm{w}$ in 3:1 of oil: $\mathrm{S}_{\text {mix }}$ ratio with $25 \mathrm{mg}$ loaded irinotecan drug produced the SNEDDS having the transmittance $>90$, with good stability.

\section{Visual observations}

Visual observations indicated that at higher levels of surfactant, the spontaneity of the self-emulsification process was increased. The formulations that have low turbidity $(<20)$ gave a transmittance values of more than 90 indicating rapid and spontaneous emulsification within $1 \mathrm{~min}$, hence it gives a good correlation between transmittance and turbidity values. All the formulations were found robust towards dilution with water, $0.1 \mathrm{~N} \mathrm{HCl}, \mathrm{pH} 4.5 \mathrm{ac}-$ etate buffer and $\mathrm{pH} 6.8$ phosphate buffer with drug precipitation within $24 \mathrm{~h}$ of storage. The drug content of all formulations ranged between $95.80 \pm 1.59$ to $99.32 \pm 1.62 \%$ with maximum value exhibited by F12 (table 4). The entrapment efficiency of all formulations varies between $95.75 \pm 1.43$ to $99.27 \pm 1.95 \%$ with maximum value displayed by F12 (table 2).

\section{In vitro dissolution tests}

The formulations F1-F16 released more than $60 \%$ of drug within 30 min, whereas, pure drug released $31.92 \%$ of drug in 60 min. Formulation F12 exhibited highest drug release of $99.06 \%$ in $60 \mathrm{~min}$.

\section{In vitro evaluation of precipitation}

In this study, the degree of supersaturation of the S-SNEDDS was determined using microcrystalline cellulose, poloxamer 407, HPMC E50LV and HPMC AS as precipitation inhibitors under non-sink conditions. There was $2 \%$ precipitation inhibitor in each formulation relative to the SNEDDS vehicle. Precipitation profiles indicated that the S-SNEDDS had more effective inhibition of irinotecan precipitation than the SNEDDS (same composition but without precipitation inhibitor) during the 60-minute experimental period. The HPMC AS displayed superior inhibition with highest drug concentration $(421.61 \mu \mathrm{g} / \mathrm{mL}$ after $60 \mathrm{~min})$. In vitro dissolution studies for S-SNEDDS of formulation F12 with 2\% HPMC AS precipitation inhibitor was studied. Comparative dissolution profiles of irinotecan pure drug, irinotecan SNEDDS and irinotecan S-SNEDDS which indicates the release of drug from irinotecan S-SNEDDS was highest with $99.96 \%$ at the end of $60 \mathrm{~min}$. (figure 6 ) 


\section{Drug compatibility study by FTIR}

The pure Irinotecan spectrum showed the main characteristic bonds at $692.47 \mathrm{~cm}^{-1}$ (C-F bending) $1039.67 \mathrm{~cm}^{-1}$ (C-O stretching), $1190.12 \mathrm{~cm}^{-1}$ (C-F stretching), 1280.78 $\mathrm{cm}^{-1}$ ( $\mathrm{C}=\mathrm{O}$ stretching), $1448.59 \mathrm{~cm}^{-1}$ (aromatic stretching), $1639.55 \mathrm{~cm}^{-1}$ (amide stretching), $1689.7 \mathrm{~cm}^{-1}(\mathrm{C}=\mathrm{C}$ stretching), $1745.64 \mathrm{~cm}^{-1}$ ( $\mathrm{C}=0$ stretching), $3026.41 \mathrm{~cm}^{-1}$ (C-H stretching), $3250.16 \mathrm{~cm}^{-1}$ (O-H stretching), $3319.6 \mathrm{~cm}^{-1}$ (N-H stretching).The presence of prominent characteristic peaks in FTIR of SNEDDS confirming the compatibility between drug and excipient.(figure 7,8)

\section{Globule size and zeta potential}

The particle size for the optimized formulation of SSNEDDS (F12) was found to be $128.23 \mathrm{~nm}$ with PDI 0.137 and the zeta potential value of $-23.45 \mathrm{mV}$. This might be the result of the addition of precipitation inhibitor HPMC AS (in S-SNEDDS) which formed a physical barrier around oil droplets and prevented them from aggregating into larger nanoemulsions. There is evidence that S-SNEDDS are more stable than plain SNEDDS due to their higher zeta potential. (figure 9A,9B)

\section{SEM studies}

The formulation appeared as spherical and smooth-surfaced and analysis of globule size was in accordance with these results with size of all droplets less than $100 \mathrm{~nm}$.

\section{Forced degradation studies}

Optimized irinotecan SNEDDS, pure drug showed no degradation even after $24 \mathrm{~h}$ storage in methanol, distilled water and $\mathrm{pH} 7.4$ phosphate buffer. Pure drug present in $0.1 \mathrm{~N}$ $\mathrm{HCl}$ solution showed $26.72 \%$ degradation within $4 \mathrm{~h}$ and the degradation was increased with time $(61.82 \%$ degradation was found at $24^{\text {th }} \mathrm{h}$ ). Irinotecan showed very less decomposition ( $<1 \%$ degradation) for up to $4 \mathrm{~h}$ and then decomposed with the time in $0.1 \mathrm{~N} \mathrm{HCl}$ solution. Irinotecan showed 12.57, 27.83 and $33.86 \%$ degradation in $6^{\text {th }}, 12^{\text {th }}$ and $24^{\text {th }} \mathrm{h}$ respectively.(table 3)

\section{Accelerated stability studies}

No visible physical changes were observed in all the formulations withdrawn from the humidity chambers. The samples were assayed for $\%$ entrapment efficiency, $\%$ drug content and in-vitro drug release and the results are shown in Table 4.

\section{CONCLUSION}

S-SNEDDS of irinotecan comprising of canola oil - caproic acid - propylene glycol system with $\mathrm{S}_{\text {mix }}$ ratio in $3: 1$ and containing 2\% HPMC AS as precipitation inhibitor were prepared for enhancing the solubility and dissolution rate of irinotecan.
S-SNEDDS were optimized based on the optimum globule size, increased dissolution and drug release. Close to complete drug release was achieved from the formulation F12 SSNEDDS which was $99.96 \%$, that is significantly higher as compared to pure drug release of $31.92 \%$ in $60 \mathrm{~min}$. The particle size for the optimized formulation of S-SNEDDS (F12) was found to be $128.23 \mathrm{~nm}$ with PDI 0.137 and the zeta potential value of $-23.45 \mathrm{mV}$. In the present study, precipitation inhibitor HPMC AS (in S-SNEDDS) was added to prevent the aggregation of oil droplets in order to produce nanoemulsions of smaller size. Thus, the developed irinotecan S-SNEDDS can be used as an effective approach for the management of cancer with relatively low drug dose with enhanced solubility and drug release.

\section{ACKNOWLEDGEMENT}

Authors acknowledge the immense help received from the scholars whose articles are cited and included in references of this manuscript. The authors are also grateful to authors / editors / publishers of all those articles, journals and books from where the literature for this article has been reviewed and discussed.

\section{Conflict of Interest}

No conflict of interest

\section{Author Contribution}

All the two authors contributed equally towards the data collection, data analysis and compilation.

\section{Financial Support}

Self-financed

\section{REFERENCES}

1. Seo DH, Jeong YII, Kim DG, Jang MJ, Jang MK, Nah JW. Methotrexate- incorporated polymeric nanoparticles of methoxy poly(ethylene glycol)-grafted chitosan. Colloids Surf B Biointerfaces 2009; 69(2):157-63.

2. Hsiang YH, Wu HY, Liu LF. Topoisomerases: novel therapeutic targets in cancer chemotherapy. Biochem Pharmacol 37(9):1988; 1801-2.

3. Liu LF. Biochemistry of camptothecin. In: Potmesil M, Pinedo H. Camptothecins: New Anticancer Agents. Ann Arbor, Mich: CRC Press; 1995:9-20.

4. Thomas N, Holm R, Müllert A, Rades T. In vitro and in vivo performance of novel supersaturated self-nanoemulsifying drug delivery systems (super-SNEDDS). J Control Release 2012; 160(1): 25-32.

5. Nguyen HA, Tun NT, Tran CS, Nguyen TD, Chi SC, Pham DV. Formulation and biopharmaceutical evaluation of supersaturatable self-nanoemulsifying drug delivery systems containing silymarin. Int J Pharm 2019; 555: 63-76.

6. Wei, Hongyan, Song J, Li H, Li Y, Zhu S, Zhou Xiaodan.Active loading liposomal irinotecan hydrochloride: Preparation, in 
vitro and in vivo evaluation. Asian J of Pharm Sci 2013; 8(5): 303-311.

7. Yosra SRE, Magda AE, Ossama YA. Self-nanoemulsifying drug delivery systems of tamoxifen citrate: design and optimization. Int J Pharm 2009; 380:133-41.

8. Feng G, Haijun Z, Jing H. Self-microemulsifying drug delivery system for improved oral bioavailability of dipyridamole: preparation and evaluation. Arch Pharm Res 2011; 34:1113-23.

9. Mantri SK, Pashikanti S, Murthy R. Development and Characterization of Self-Nanoemulsifying Drug Delivery Systems (SNEDDS) of Atorvastatin Calcium. Current Drug Delivery 2012; 9: 182.

10. Sunny R. Shah, Rajesh H. Parikh, Jayant R. Chavda. Self-Nanoemulsifying Drug Delivery System of Glimepiride: Design, Development, and Optimization. PDA J Pharm Sci and Tech 2013; 67: 201-213.

11. Khoo SM, Humberstone AJ, Porter CJ, Edwards GA, Charman WN. Formulation design and bioavailability assessment of lipidic self-emulsifying formulations of halofantrine. Int J Pharm 1998; 167:155-64.

12. Kommuru TR, Gurley B, Khan MA, Reddy IK. Self-emulsifying drug delivery systems (SEDDS) of coenzyme Q10: formulation development and bioavailability assessment. Int J Pharm 2001; 212: 233-246.

13. Ping Z, Ying L, Nianping F, Jie X. Preparation and evaluation of self-microemulsifying drug delivery system of oridonin. Int $\mathbf{J}$ Pharm 2008;355:269-76

14. Patel J, Kevin G, Patel A, Raval M, Sheth N. Design and development of a self-nanoemulsifying drug delivery system for telmisartan for oral drug delivery. Int J Pharm Investig 2011;1(2):112-118.
15. Rachmawati H, Soraya IS, Kurniati NF, Rahma A. In Vitro Study on Antihypertensive and Anti hypercholesterolemic effects of a Curcumin Nanoemulsion. Sci Pharm 2016;84(1):131-140.

16. Barish. Formulation and evaluation of Irinotecan hydrochloride nanoparticles for the treatment of colorectal cancer. Int J of Res in Pharm and Nano Sciences2015; 4(4):260 - 268.

17. Goudanavar P, Kumar S. Development and characterization of Irinotecan loaded colloidal drug delivery system. J of Pharm Sci and Res 2018; 10: 434-438.

18. Aldawsari HM, Elfaky MA, Fahmy UA, Aljaeid BM, Alshareef OA. Development of a fluvastatin-loaded self-nanoemulsifying system to maximize therapeutic efficacy in human colorectal carcinoma cells. J of Drug Deli Sci and Techn 2018; 46: 7-13.

19. Ravula AR, Nagabandi V, Parney S. Encapsulation of selfemulsifying drug delivery systems (SEDDS) of lercanidipine hydrochloride into hard gelatin capsules. Int J Biopharm 2014; 5: 73-82

20. Czajkowska-Kośnik A, Szekalska M, Amelian A, Szymańska, Winnick K. Development and Evaluation of Liquid and Solid Self-Emulsifying Drug Delivery Systems for Atorvastatin. Molecules 2015; 20(12): 21010-21022.

21. Somnath P, Swati J, Shailendra K, Varsha D. Formulation And Evaluation Of Xanthan Gum Based Floating Tablet Of Tramadol Hydrochloride. Int J Cur Res Rev 2012;4(17):172-180.

22. 22. Darshana R, Fahimuddin S, Debarshi K, Ujwala N. Comparative Quality Analysis of Cefpodoxime Proxetil Branded Tablet Product with Available Indian Generic Products: ShortTerm Accelerated Study. Int J Cur Res Rev 2021;13(7):172-184.

\section{Table 1: Composition of irinotecan SNEDDS}

\begin{tabular}{lcccccc} 
S. No & $\begin{array}{c}\text { Formulation } \\
\text { code }\end{array}$ & $\begin{array}{c}\text { Irinotecan } \\
\text { drug }(\mathbf{m g})\end{array}$ & Ratios of Oil: $\mathrm{S}_{\text {mix }}$ & $\begin{array}{c}\text { Oil } \\
\text { (Canola oil) }\end{array}$ & $\begin{array}{c}\text { Surfactant }_{\text {mix }}^{3: 1} \\
\text { (Caproic acid) }\end{array}$ & $\begin{array}{c}\text { Co-surfactant } \\
\text { (Propylene glycol) }\end{array}$ \\
\hline 1 & F1 & 25 & $01: 01$ & 50 & 37.5 & 12.5 \\
2 & F2 & 25 & $01: 02$ & 33 & 49.5 & 16.5 \\
3 & F3 & 25 & $01: 03$ & 25 & 56.25 & 18.75 \\
4 & F4 & 25 & $03: 01$ & 75 & 18.75 & 6.25 \\
5 & F5 & 25 & $02: 01$ & 66 & 24.75 & 8.25 \\
6 & F6 & 25 & $02: 03$ & 40 & 45 & 15 \\
7 & F7 & 25 & $08: 03$ & 72.7 & 20.25 & 6.75 \\
8 & F8 & 25 & $07: 03$ & 70 & 22.5 & 7.5 \\
9 & F9 & 25 & $05: 03$ & 62.5 & 28.12 & 9.3 \\
10 & F10 & 25 & $04: 03$ & 57.1 & 31.95 & 10.65 \\
11 & F11 & 25 & $02: 05$ & 28.5 & 53.25 & 17.75 \\
12 & F12 & 25 & $02: 07$ & 22.2 & 58.2 & 19.4 \\
13 & F13 & 25 & $03: 02$ & 60 & 30 & 10 \\
14 & F14 & 25 & $03: 04$ & 42.6 & 42.6 & 14.8 \\
15 & F15 & 25 & $03: 07$ & 30 & 52.5 & 17.5 \\
16 & F16 & 25 & $05: 02$ & 71 & 21.3 & 7.1 \\
\hline
\end{tabular}


Table 2: \% drug content and \% entrapment efficiency values

\begin{tabular}{lcc} 
Formulation code & \%Drug content & \% Entrapment Efficiency \\
F1 & $97.61 \pm 1.21$ & $97.76 \pm 1.43$ \\
F2 & $98.21 \pm 1.19$ & $98.37 \pm 1.51$ \\
F3 & $98.95 \pm 1.65$ & $98.93 \pm 1.69$ \\
F4 & $95.80 \pm 1.59$ & $95.75 \pm 1.43$ \\
F5 & $96.53 \pm 1.19$ & $96.48 \pm 1.22$ \\
F6 & $98.03 \pm 1.49$ & $98.08 \pm 1.67$ \\
F7 & $95.93 \pm 1.78$ & $95.88 \pm 1.53$ \\
F8 & $96.14 \pm 1.15$ & $96.09 \pm 1.79$ \\
F9 & $96.85 \pm 1.66$ & $96.80 \pm 1.73$ \\
F10 & $97.40 \pm 1.45$ & $97.39 \pm 1.35$ \\
F11 & $98.81 \pm 1.13$ & $98.76 \pm 1.39$ \\
F12 & $99.32 \pm 1.62$ & $99.27 \pm 1.95$ \\
F13 & $97.21 \pm 1.89$ & $97.16 \pm 1.84$ \\
F14 & $97.97 \pm 1.39$ & $97.91 \pm 1.70$ \\
F15 & $98.47 \pm 0.72$ & $98.52 \pm 0.54$ \\
F16 & $96.07 \pm 1.39$ & $95.91 \pm 1.70$ \\
\hline
\end{tabular}

Table 3: Percent Degradation of irinotecan from Pure Drug and Optimized irinotecan SNEDDS in Forced Degradation Study

\begin{tabular}{|c|c|c|c|c|c|c|}
\hline \multirow{2}{*}{$\begin{array}{l}\text { Formulation } \\
\text { code }\end{array}$} & \multirow{2}{*}{$\begin{array}{l}\text { Time (hr) / Dilut- } \\
\text { ing Solvent }\end{array}$} & \multicolumn{5}{|c|}{$\%$ Drug Degraded $(\%$, mean $\pm S D, n=3)$} \\
\hline & & o Hour & $4^{\text {th }}$ Hour & $6^{\text {th }}$ Hour & $12^{\text {th }}$ Hour & $24^{\text {th }}$ Hour \\
\hline \multirow[t]{4}{*}{ Pure drug } & Methanol & $0.02 \pm 0.26$ & $0.012 \pm 1.02$ & $0.03 \pm 0.29$ & $0.012 \pm 2.02$ & $0.10 \pm 1.09$ \\
\hline & Water & $0.02 \pm 1.03$ & $0.01 \pm 1.19$ & $0.03 \pm 0.19$ & $0.04 \pm 1.02$ & $0.04 \pm 2.00$ \\
\hline & $0.1 \mathrm{~N} \mathrm{HCl}$ & $0.07 \pm 1.35$ & $26.72 \pm 1.72$ & $29.83 \pm 0.27$ & $42.01 \pm 0.37$ & $61.82 \pm 0.27$ \\
\hline & $\begin{array}{l}\mathrm{pH} 7.4 \text { phosphate } \\
\text { Buffer }\end{array}$ & $0.02 \pm 0.93$ & $0.03 \pm 1.36$ & $0.11 \pm 1.92$ & $0.06 \pm 1.27$ & $0.08 \pm 1.72$ \\
\hline \multirow{4}{*}{$\begin{array}{l}\text { F12 } \\
\text { (S-SNEDDS) }\end{array}$} & Methanol & $0.02 \pm 1.27$ & $0.12 \pm 0.29$ & $0.17 \pm 1.73$ & $0.03 \pm 1.08$ & $0.01 \pm 0.72$ \\
\hline & Water & $0.01 \pm 1.57$ & $0.22 \pm 0.37$ & $0.02 \pm 1.22$ & $0.11 \pm 1.17$ & $0.07 \pm 1.27$ \\
\hline & $0.1 \mathrm{~N} \mathrm{HCl}$ & $0.02 \pm 1.94$ & $0.04 \pm 1.23$ & $12.57 \pm 1.06$ & $27.83 \pm 0.03$ & $33.86 \pm 0.72$ \\
\hline & $\begin{array}{l}\mathrm{pH} 7.4 \text { phosphate } \\
\text { Buffer }\end{array}$ & $0.01 \pm 0.86$ & $0.05 \pm 0.27$ & $0.07 \pm 0.28$ & $0.02 \pm 0.27$ & $0.12 \pm 0.86$ \\
\hline
\end{tabular}

Above parameters are communicated as Average \pm Standard Deviation; $(n=3)$

Table 4: Storage at $40 \pm 2^{\circ} \mathrm{C} / 75 \pm 5 \%$ RH for 6 months

\begin{tabular}{lccc}
$\begin{array}{l}\text { Retest time for optimized } \\
\text { formulation F12 (S-SNEDDS) }\end{array}$ & \% Drug content & Entrapment efficiency (\%) & In-vitro drug release (\%) \\
\hline o days & $99.32 \pm 1.50$ & $99.27 \pm 0.50$ & $99.96 \pm 0.93$ \\
30 days & $99.06 \pm 0.15$ & $99.01 \pm 0.39$ & $99.63 \pm 0.37$ \\
6o days & $98.72 \pm 0.96$ & $98.82 \pm 1.60$ & $99.32 \pm 1.26$ \\
90 days & $98.41 \pm 0.48$ & $98.47 \pm 1.72$ & $98.97 \pm 0.67$ \\
180 days & $98.09 \pm 0.75$ & $98.05 \pm 0.41$ & $98.75 \pm 0.24$ \\
\hline
\end{tabular}

Above parameters are communicated as Average \pm Standard Deviation; $(n=3)$ 


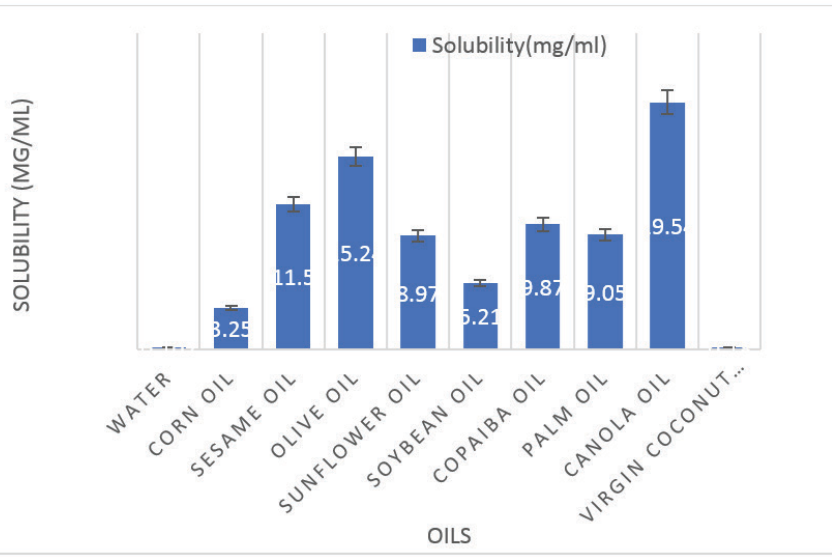

Figure 1: Solubility of irinotecan in various oils.

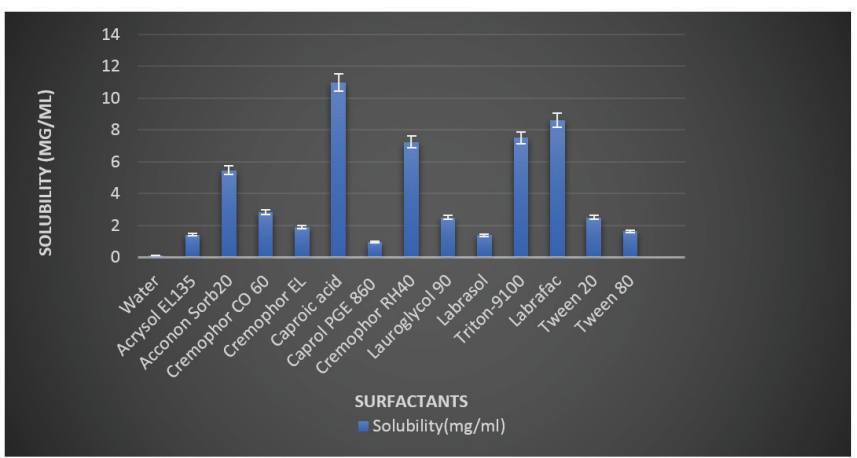

Figure 2: Solubility of irinotecan in various surfactants.

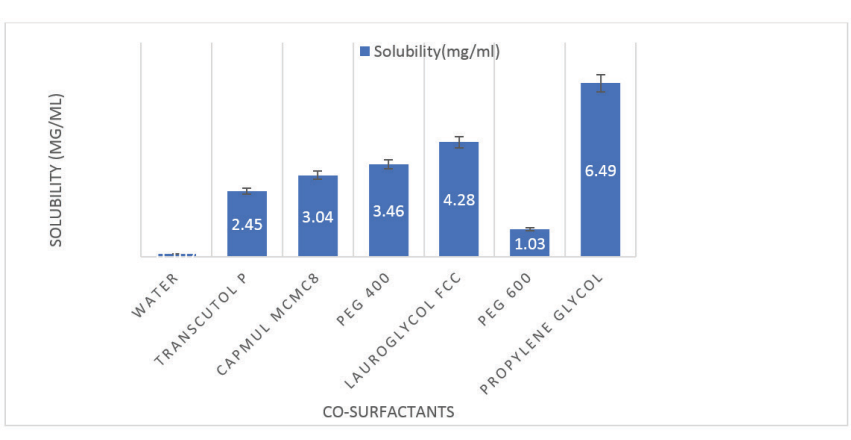

Figure 3: Solubility of irinotecan in various co-surfactants

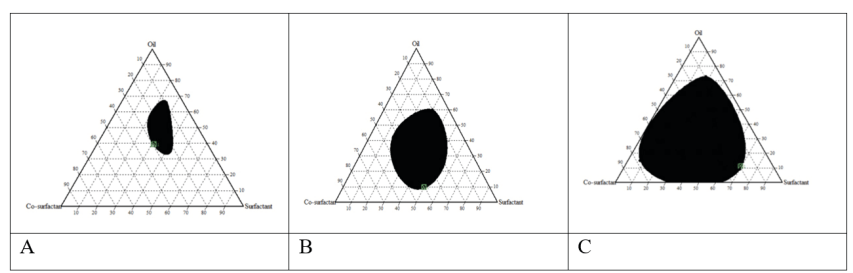

Figure 4: Ternary phase diagram for Canola oil - caproic acid propyleneglycolwith $_{\text {mix }}$ in 1:1 $\operatorname{ratio}(A): 2: 1$ ratio(B)and3:1 ratio(C) (Key: the filled region within the ternary phase diagram indicates nanoemulsification area where the transmittance is greater than 90).

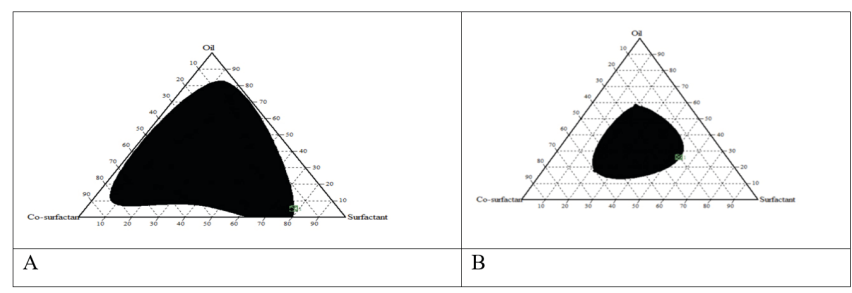

Figure 5: Ternary phase diagram for $25 \mathrm{mg}(\mathrm{A})$ and $50 \mathrm{mg}(\mathrm{B})$ of irinotecan loaded in Canola oil - Caproic acid - Propylene glycol system with $S_{\text {mix }}$ in 3:1 ratio (Key: the filled region within the ternary phase diagram indicates nanoemulsification area where the transmittance is greater than 90).

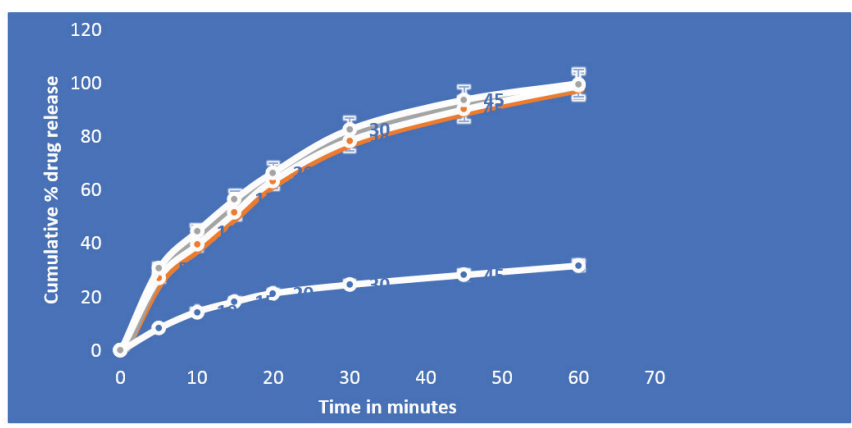

Figure 6: Comparative dissolution profiles of irinotecan pure drug, irinotecan SNEDDS and irinotecan S-SNEDDS.

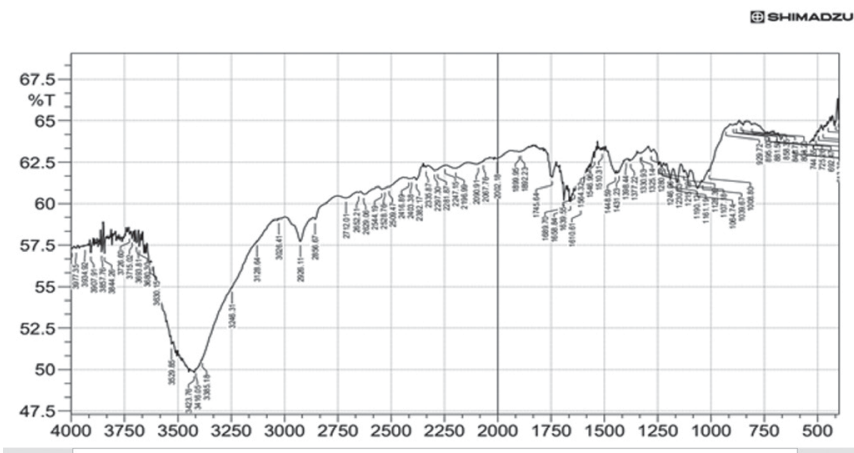

Figure 7: FTIR spectrum of pure drug irinotecan.

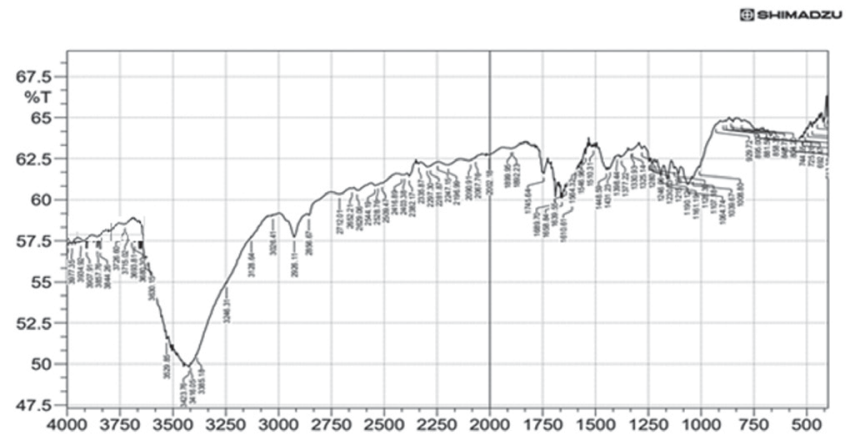

Figure 8: FTIR spectrum of irinotecan S-SNEDDS (F12). 


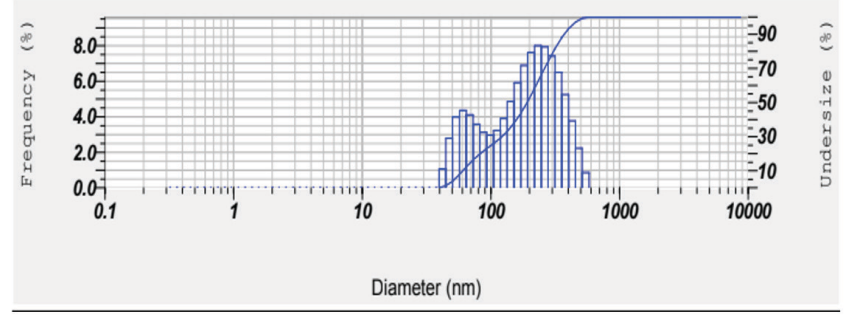

Figure 9A: Particle size of optimised SNEDDS formulation of irinotecan (F12).

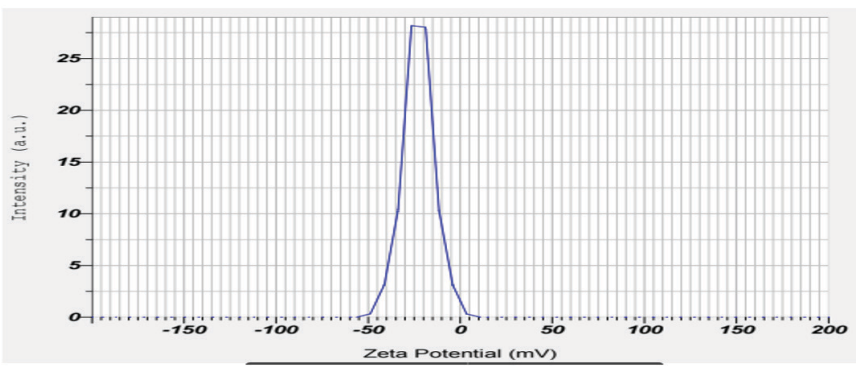

Figure 9B: Zeta potential of optimised SNEDDS formulation of irinotecan (F12).

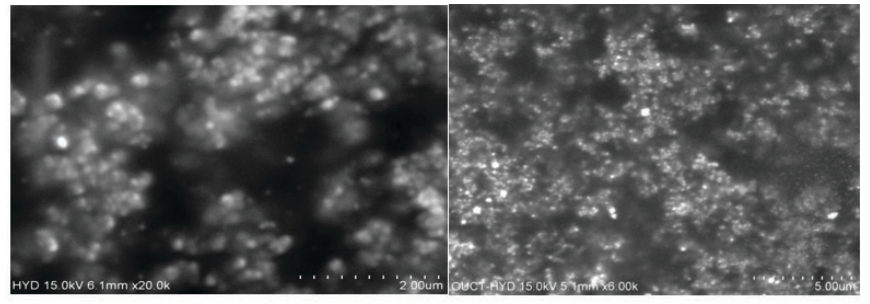

10(A)

10(B)

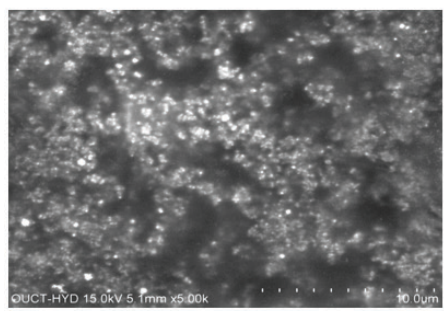

$10(C)$

Figure 10: SEM images of optimised formulation of irinotecan SNEDDS F12 (A, B\& C). 